\title{
Inhibitory Effects of Oncoba Spinosa on Key Enzymes Related to Diabetes Mellitus ( $\alpha$-Amylase and $\alpha$-Glucosidase) and Obesity (Pancreatic Lipase) in Vitro
}

\author{
Prasanth Kumar $\mathbf{M}^{1 *}$, Suba $\mathbf{V}^{2}$, Rami Reddy $\mathbf{B}^{3}$ and Srinivasa Babu $\mathbf{P}^{1}$ \\ ${ }^{1}$ Vignan Pharmacy College, Vadlamudi, Guntur, Andhra Pradesh, India \\ ${ }^{2}$ Department of Pharmacology, National Institute of Siddha, Chennai, India \\ ${ }^{3}$ Director-Formulations, NATCO Pharma, Hyderabad, India \\ *Corresponding author: Prasanth Kumar M, Vignan Pharmacy College, Vadlamudi, Guntur, Andhra Pradesh, India, Tel: +91-9566243547; E-mail: \\ Prasanth.Pharmacology@gmail.com
}

Received date: November 20, 2017; Accepted date: December 27, 2017; Published date: December 29, 2017

Copyright: @ 2017 Kumar PM, et al. This is an open-access article distributed under the terms of the Creative Commons Attribution License, which permits unrestricted use, distribution, and reproduction in any medium, provided the original author and source are credited.

\section{Abstract}

Aim and Objective: Oncoba spinosa Forssk. (Flacourtiaceae) (OS) is traditionally used for the management of diabetes mellitus. In previous studies, we studied the effect of OS on $\alpha$-amylase and a-glucosidase inhibition, however the effect of OS on pancreatic lipase inhibition and kinetics of $\alpha$-amylase, $\alpha$-glucosidase and pancreatic lipase inhibition were not studied. This study determined the in vitro inhibitory effects of OS against pancreatic lipase and characterized the kinetics of $\alpha$-amylase, $\alpha$-glucosidase and pancreatic lipase inhibition.

Materials and Methods: Dried powdered roots were successively extracted with various solvents such as petroleum ether, chloroform, ethyl acetate, and $70 \%$ ethanol. The successive extracts obtained $(62.5-1000 \mu \mathrm{g} / \mathrm{ml})$ were subjected to in vitro pancreatic lipase inhibitory assay and the most active extract was selected for kinetic studies.

Results: Of all the successive extracts studied, the ethanolic extract showed highest pancreatic lipase inhibitory activity. The ethanolic extract showed mixed type of inhibition against $\alpha$-amylase and pancreatic lipase whereas non-

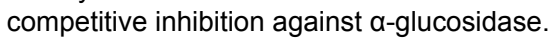

Conclusion: The data of this study suggests that OS inhibits amylase, glucosidase and lipase activities, which leads to a reduction in the intestinal absorption of carbohydrates and lipids.

Keywords: Oncoba spinosa; Diabetes mellitus; $\alpha$-glucosidase; $\alpha$ amylase; Pancreatic lipase; Kinetics

\section{Introduction}

Obesity and diabetes reduce quality of life as well as shorten lifespan. As a result, huge sums of money have been spent by individuals and governments to cure these diseases [1]. Acarbose and miglitol are the two currently marketed glucosidase inhibitors for the treatment of type 2 diabetes mellitus. Two major side effects-diarrhoea and abdominal pain- have limited their use in the clinical arena [2]. Orlistat, a pancreatic lipase inhibitor, is the only drug approved by the U.S. Food and Drug Administration for long-term treatment of obesity. However, orlistat may produce undesirable adverse events such as steatorrhea, fecal urgency or incontinence, and bowel movement urgency [3]. For these reasons several research groups addressed their activity on the discovery of natural products with inhibitory potential on key enzymes related to type 2 diabetes and obesity.

Oncoba spinosa Forssk (OS) belonging to the family Flacourtiaceae is a small tree of about $13 \mathrm{~m}$ high which grows under conditions of higher rainfall, of deciduous, secondary and fringing forest from Senegal to West Cameroon, and widely distributed in tropical Africa and Arabia [4]. Ethnopharmacological data has revealed that OS has been extensively used for the treatment of diabetes and cancer in Nigeria region [5]; leaves and roots are used in African countries for the treatment of urethral discharges, infertility, epilepsy, dysentery and bladder conditions [6-8]; fruits are used for the treatment of syphilis, wounds, parasitic worms, and sexual impotence [9]. a-glucosidase inhibitory, radical scavenging and cytotoxicity activities of OS leaves have been reported. Earlier studies carried out by us have shown that ethanolic extract of OS roots demonstrated highest $\alpha$-amylase and $\alpha$ glucosidase inhibition when compared to other extracts studied [10]. Previous studies did not incorporate the inhibitory activity of the extracts on pancreatic lipase and the mode of inhibition on $\alpha$-amylase, a-glucosidase and pancreatic lipase. We report here the pancreatic lipase inhibitory activity of the extract and kinetics of all three enzymes $\alpha$-amylase, $\alpha$-glucosidase and pancreatic lipase action of the plant extract.

\section{Materials and Methods}

\section{Chemicals}

$\alpha$-amylase, porcine pancreatic lipase, PNPG (4-nitrophenyl $\alpha$-dglucopyranoside) and a-glucosidase were purchased from Sigma Aldrich, USA. Other chemicals and reagents were purchased from Merck. 
Citation: Kumar PM, Suba V, Reddy RB, Babu SP (2017) Inhibitory Effects of Oncoba Spinosa on Key Enzymes Related to Diabetes Mellitus ( $\alpha$ Amylase and a-Glucosidase) and Obesity (Pancreatic Lipase) in Vitro. J Diabetes Metab 8: 781. doi:10.4172/2155-6156.1000781

Page 2 of 5

\section{Collection and identification of the plant materials}

The roots of Oncoba spinosa were collected from Chittoor district, Andhra Pradesh and positively identified by Dr. Madhava chetty, Botanist, S.V. University, Tirupathi. A voucher specimen of the collected sample was deposited in the herbarium of the institution for future reference.

\section{Preparation of the extract}

The roots of the plant were shade-dried, and powdered. The powdered material was sequentially extracted with petroleum ether chloroform, ethyl acetate, and $70 \%$ ethanol for $72 \mathrm{~h}$ using maceration to produce the respective extracts. All the extracts were vaccum dried to obtain petroleum ether extract (PEOS), chloroform extract (CEOS), ethyl acetate extract (EAOS) and ethanol extract (EEOS) respectively.

\section{Pancreatic lipase inhibition}

The pancreatic lipase inhibitory activity was determined as described by Bustanji et al 2010 with modifications [11]. A volume of $50 \mu \mathrm{l}$ pancreatic lipase solution $(1 \mathrm{mg} / \mathrm{ml}$ in $2.5 \mathrm{mM}$ tris-hydrochloride buffer pH 7.4 with $0.125 \mathrm{mM}$ sodium chloride) was pre-mixed with $100 \mu \mathrm{l}$ extract (initial concentrations used ranged from 62.5-1000 $\mu \mathrm{g} / \mathrm{ml}$ for successive extracts) and incubated at $37^{\circ} \mathrm{C}$ for $15 \mathrm{~min}$. Following pre-incubation, $100 \mu \mathrm{l}$ p-nitrophenyl butyrate (PNPB) $(1.25$ $\mathrm{mM}$ ) was added to the enzyme-extract mixture and the volume was made up to $300 \mu \mathrm{l}$ using tris-hydrochloride buffer. The reaction mixture was incubated at $37^{\circ} \mathrm{C}$ for $60 \mathrm{~min}$ and the amount of p-nitrophenol released was measured at $405 \mathrm{~nm}$. The concentration of sample required to inhibit pancreatic lipase activity by $50 \%\left(\mathrm{IC}_{50}\right)$ under assay conditions was calculated from the percentage inhibition values.

\section{a-Amylase kinetic studies}

The mode of inhibition on the root extract was determined as described by Mohammed et al 2017 with slight modifications [12]. The extract with the lowest $\mathrm{IC}_{50}$ value in our previous studies was selected for the study. The inhibition mode of the extract on a-amylase was studied with increasing concentrations $(0.063-1 \%)$ of starch substrate, in the presence and absence of the extract. A double reciprocal plot $(1 / \mathrm{V}$ versus $1 / \mathrm{S})$ where $\mathrm{V}$ is reaction velocity and $\mathrm{S}$ is substrate concentration was plotted. The type (mode) of inhibition of the ethanolic extract on $a$-amylase activity was determined by analysis of the double reciprocal (Lineweaver-Burk) plot using Michaelis-Menten kinetics.

\section{a-Glucosidase kinetic studies}

The mode of inhibition of the root extract was determined as described by Mohammed et al. with slight modifications [12]. The extract with the lowest $\mathrm{IC}_{50}$ value in our previous studies was selected for the study. The inhibition mode of the extract on $\alpha$-glucosidase was studied with increasing concentrations $(0.313-5 \mathrm{mM})$ of PNPG substrate, in the presence and absence of the extract. A double reciprocal plot $(1 / \mathrm{V}$ versus $1 / \mathrm{S})$ where $\mathrm{V}$ is reaction velocity and $\mathrm{S}$ is substrate concentration was plotted. The type (mode) of inhibition of the ethanolic extract on -glucosidase activity was determined by analysis of the double reciprocal (Lineweaver-Burk) plot using Michaelis-Menten kinetics.

\section{Pancreatic lipase kinetic studies}

The extract with the lowest $\mathrm{IC}_{50}$ value was selected for the study. The inhibition mode of the extract on pancreatic lipase was assayed with increasing concentrations $(0.125-1.25 \mathrm{mM})$ of synthetic substrate, $\mathrm{p}$ nitrophenyl butyrate (PNPB), in the presence and absence of the extract. A double reciprocal plot $(1 / \mathrm{V}$ versus $1 / \mathrm{S})$ where $\mathrm{V}$ is reaction velocity and $S$ is substrate concentration was plotted. The type (mode) of inhibition of the ethanolic extract on pancreatic lipase activity was determined by analysis of the double reciprocal (Lineweaver-Burk) plot using Michaelis-Menten kinetics.

\section{Statistical analysis}

The data were expressed as the mean \pm SEM of three replicates. Analysis was performed using Graphpad Software and Excel 2010. Values were considered significantly different at $\mathrm{p}<0.05$.

\section{Results}

\section{Pancreatic lipase inhibition}

\begin{tabular}{|c|c|c|c|c|c|c|}
\hline \multirow{2}{*}{ Test Substance } & \multicolumn{5}{|c|}{$\%$ Inhibition Concentration $(\mu \mathrm{g} / \mathrm{ml})$} & \multirow{3}{*}{$\begin{array}{c}\mathrm{IC}_{50}(\boldsymbol{\mu g} / \mathrm{ml}) \\
-\end{array}$} \\
\hline & $62.5 \mu \mathrm{g} / \mathrm{ml}$ & $125 \mu \mathrm{g} / \mathrm{ml}$ & $250 \mu \mathrm{g} / \mathrm{ml}$ & $500 \mu \mathrm{g} / \mathrm{ml}$ & $1000 \mu \mathrm{g} / \mathrm{ml}$ & \\
\hline PEOS & - & - & - & - & - & \\
\hline CEOS & $5.03 \pm 1.21$ & $8.33 \pm 0.63$ & $12.23 \pm 1.00$ & $20.26 \pm 1.33$ & $27.73 \pm 1.70$ & $>1000$ \\
\hline EAOS & $8.18 \pm 1.01$ & $11.13 \pm 1.15$ & $26.60 \pm 0.72$ & $35.93 \pm 0.85$ & $53.13 \pm 0.39$ & $909.46 \pm 5.88$ \\
\hline EEOS & $12.43 \pm 1.06$ & $22.53 \pm 1.27$ & $39.13 \pm 1.14$ & $52.83 \pm 0.31$ & $70.40 \pm 0.66$ & $447.57 \pm 6.97$ \\
\hline Orlistat (Standard) & $28.76 \pm 0.86$ & $37.60 \pm 0.52$ & $46.13 \pm 0.44$ & $59.36 \pm 0.56$ & $72.70 \pm 1.15$ & $322.98 \pm 6.80$ \\
\hline
\end{tabular}

Table 1: Pancreatic lipase inhibitory activity of $O$. spinosa root extracts.

The petroleum ether extract failed to inhibit pancreatic lipase activity. The pancreatic lipase inhibitory effect of CEOS was found to be ranging from $5.03 \pm 1.21 \%$ to $27.73 \pm 1.70 \%$. The pancreatic lipase inhibitory effect of EAOS was found to be ranging from $8.18 \pm 1.01 \%$ to $53.13 \pm 0.39 \%$ when studied at concentrations $62.5-1000 \mu \mathrm{g} / \mathrm{ml}$. At same concentration, the inhibitory effect of EEOS was found to be 
Citation: Kumar PM, Suba V, Reddy RB, Babu SP (2017) Inhibitory Effects of Oncoba Spinosa on Key Enzymes Related to Diabetes Mellitus ( $\alpha$ Amylase and a-Glucosidase) and Obesity (Pancreatic Lipase) in Vitro. J Diabetes Metab 8: 781. doi:10.4172/2155-6156.1000781

Page 3 of 5

ranging from $12.43 \pm 1.06 \%$ to $70.40 \pm 0.66 \%$ whereas the effect of the standard drug Orlistat, ranged from $28.76 \pm 0.86 \%$ to $72.70 \pm 1.15 \%$ The $\mathrm{IC}_{50}$ value of ethyl acetate extract, EAOS was found to be 909.46 $\mu \mathrm{g} / \mathrm{ml}$ whereas the ethanolic extract, EEOS showed at $447.57 \mu \mathrm{g} / \mathrm{ml}$. The $\mathrm{IC}_{50}$ of Orlistat was found to be $322.98 \mu \mathrm{g} / \mathrm{ml}$ (Table 1).

\section{a-Amylase kinetic studies}

Since the highest inhibitory activity was observed with ethanolic extract in our previous studies, kinetic studies were performed on this extract. The double reciprocal plot displayed mixed type of inhibition of $\alpha$-amylase action by the ethanolic extract of OS (Figure 1). Both the $\mathrm{K}_{\mathrm{m}}$ value and $\mathrm{V}_{\max }$ value were altered.

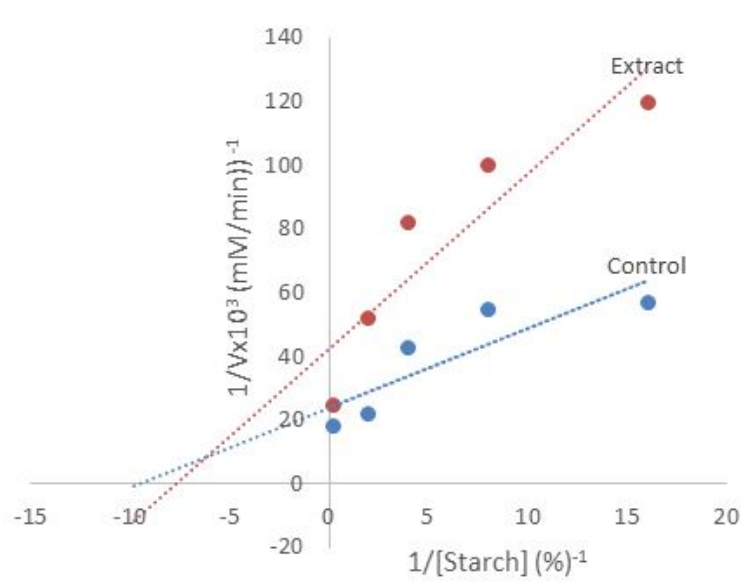

Figure 1: Lineweaver-Burke plot for $\alpha$-amylase in the absence and presence of the ethanolic extract of $O$. spinosa.

\section{a-Glucosidase kinetic studies}

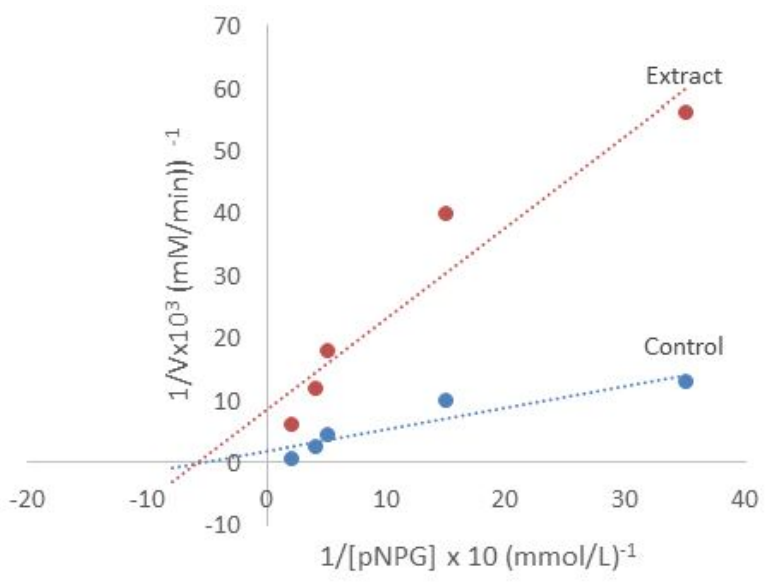

Figure 2: Lineweaver-Burke plot for $\alpha$-glucosidase in the absence and presence of the ethanolic extract of $O$. spinosa.
Since the highest inhibitory activity was observed with ethanolic extract in our previous studies, kinetic studies were performed on this extract. The double reciprocal plot displayed non-competitive inhibition of $\alpha$-glucosidase action by the ethanolic extract of OS (Figure 2). The $\mathrm{K}_{\mathrm{m}}$ value was unaltered and $\mathrm{V}_{\max }$ value was reduced.

\section{Pancreatic lipase kinetic studies}

The highest inhibitory activity was observed with ethanolic extract, kinetic studies were performed on this extract. The double reciprocal plot displayed mixed type of inhibition of pancreatic lipase action by the ethanolic extract of OS (Figure 3). Both the $\mathrm{K}_{\mathrm{m}}$ value and $\mathrm{V}_{\max }$ value were altered.

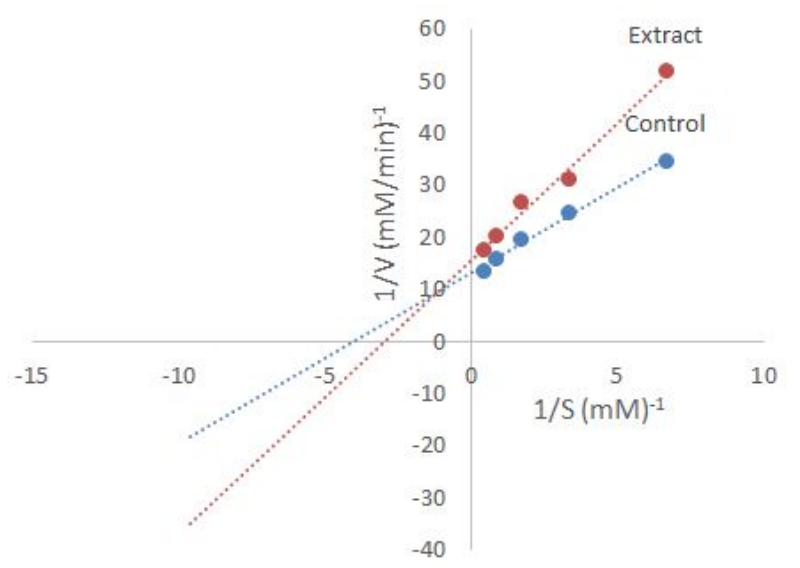

Figure 3: Lineweaver-Burke plots for pancreatic lipase in the absence and presence of the ethanolic extract of $O$. spinosa.

\section{Discussion}

Medicinal plants were among the first plants to be utilized by humankind. Many species have been known from time immemorial to have medicinal properties. Over thousands of years, human observation has served as the basis for the preparation of medicines that led to the emergence of the production of modern industrial pharmaceuticals [13]. OS is a medicinal plant which has been extensively used in south west of Nigeria to manage various diseases including diabetes and cancer. However, there is no scientific data available on the inhibitory activities of OS on key enzymes linked to diabetes mellitus and obesity. Obesity is caused by excess caloric intake, and this can be improved by inhibiting pancreatic lipase activity and by inhibiting or delaying lipid absorption. Inhibition of carbohydrate hydrolysing enzymes and inhibition of carbohydrate absorption also play an important role in the prevention and treatment of diabetes. In this study, we performed in vitro experiments to study the effect of OS on pancreatic lipase activity and the kinetics of $\alpha$ amylase, $\alpha$-glucosidase and pancreatic lipase inhibition.

Findings from our previous study showed that OS crude ethanolic extract displayed highest $\alpha$-amylase and $\alpha$-glucosidase inhibition when compared to other extracts studied. Interestingly, the crude ethanolic extract showed low inhibitory potential on a-amylase and stronger action on $\alpha$-glucosidase [10]. These results are in agreement with previous reports which indicated that excessive inhibition of 
pancreatic $a$-amylase could result in the abnormal bacterial fermentation of undigested carbohydrates in the colon and eventually flatulence, abdominal distension and diarrhoea. Thus, stronger inhibition of $a$-glucosidase activity and mild inhibition of $a$-amylase activity could address the major drawback of currently used hypoglycaemic drugs $[14,15]$. The results of the present study showed that OS crude ethanolic extract showed highest pancreatic lipase inhibitory activity in a dose dependent manner when compared to other extracts studied. Interestingly, data from the present study demonstrated that OS was a potent inhibitor of enzymes directly linked to diabetes mellitus and obesity. Kinetic studies on the most active crude extract showed that the crude ethanolic extract exerted two modes of inhibitions, namely the noncompetitive and mixed type mechanisms. Lineweaver-Burk plot showed that crude ethanolic extract of OS displayed a mixed type of inhibition on $a$-amylase and pancreatic lipase. On the other hand, a-glucosidase was noncompetitively inhibited by the crude ethanolic extract. In mixed type of inhibition, the inhibitor binds to either free enzyme or enzyme substrate complex, with effect on $\mathrm{K}_{\mathrm{m}}$ and $\mathrm{V}_{\max }$ of the reaction. In non-competitive type of inhibition, the inhibitor binds to either free enzyme or enzyme substrate complex, with no effect on $\mathrm{K}_{\mathrm{m}}$ but results in a decrease in $\mathrm{V}_{\max }$ of the reaction [16]. It is therefore suggested that active constituents in the extract bind to other site(s), apart from the active site of the enzyme and induced a conformational change in the threedimensional structure of the enzymes and ultimately slowed down their activities [12].

The inhibitory effect of OS on $\alpha$-amylase, $\alpha$-glucosidase and pancreatic lipase could be as a result of the phytochemicals present such as tannins, flavonoids and phenolic compounds. The $\alpha$ glucosidase inhibition capacity of phenolic compounds is mainly due to their protein-binding capability [17]. Phenolic compounds have been shown to stimulate thermogenesis and body fat oxidation, thereby beneficial in the reduction of body weight $[18,19]$. Tannins induce insulin receptor phosphorylation as well as activation of translocation of glucose transporter 4 (GLUT-4), the main insulinresponsive glucose transporter [20]. The presence of hydroxyl group in the structure of flavonoids is also responsible for their antioxidant and antidiabetic effects [21]. Flavonoids, the powerful chain-breaking antioxidants (powerful electron donors) are also responsible for inhibition of lipid peroxidation. Flavonoids have been reported to prevent oxidative stress induced $\beta$-cell dysfunction, therefore alter the progression of insulin resistance to type 2 diabetes [22].

\section{Conclusion}

It can be concluded from this study that out of the four extracts of Oncoba spinosa tested, the ethanolic extract displayed the most effective inhibition of pancreatic lipase in vitro and the mode of inhibition of both pancreatic lipase and a-amylase is the mixed type one whereas the mode of inhibition of $\alpha$-glucosidase is the noncompetitive one. The potent inhibitory activities of this plant may be due to the synergistic effect of phytochemicals present in it. Further in vivo antidiabetic and antiobesity studies of $O$. Spinosa are to be carried out in experimental models.

\section{Acknowledgements}

The authors wish to thank and appreciate the management of Vignan Pharmacy College for providing necessary facilities to carry out the research work.

\section{References}

1. Olshansky SJ, Passaro DJ, Hershow RC, Layden J, Carnes BA, et al. (2005) A potential decline in life expectancy in the United States in the 21st century. New Engl J Med 352: 1135-1137.

2. Irons BK, Minze MG (2014) Drug treatment of type 2 diabetes mellitus in patients for whom metformin is contraindicated. Diabetes Metab Syndr Obes 7: 15-24.

3. Guo L, Gao Z, Zhang L, Guo F, Chen Y, Li Y, et al. (2016) Saponinenriched sea cucumber extracts exhibit an antiobesity effect through inhibition of pancreatic lipase activity and upregulation of LXR- $\beta$ signalling. Pharm Biol 54: 1312-1325.

4. Hutchinson J, Dalziel JM (1954) Flacourtiaceae. In: Keay RWJ, (editors) Flora of West Tropical Africa. London: Crown Agents for Overseas Governments and Administration; pp: 185-191.

5. Balogun OS, Oladosu IA, Akinnusi A, Zhiqiang L (2013) Fatty acids composition, $\alpha$-glucosidase inhibitory potential and cytotoxicity activity of Oncoba spinosa Forssk. Elixir Appl Chem 59: 15637-15641.

6. Arnold HJ, Gulumian M (1984) Pharmacopoeia of traditional medicine in Venda. J Ethnopharmacol 12: 35-74.

7. Tabuti JR, Lye KA, Dhillion SS (2003) Traditional herbal drugs of Bulamogi, Uganda: plants, use and administration. J Ethnopharmacol 88: 19-44.

8. Malgras DRP (1992) Arbres et arbustes guérisseurs des savanes maliennes. 22-24, boulevard Arago, 75013 Paris: Karthala.

9. Balogun OS, Ajayi OS, Lawal OS (2016) Isolation and Cytotoxic Investigation of Flacourtin from Oncoba spinosa. Medicines 3: 31 .

10. Prasanth Kumar M, Suba V, Ramireddy B, Srinivasa Babu P (2015) In vitro antidiabetic and in vivo antidiarrheal activity of Oncoba spinosa roots. Indonesian J Pharm 26: 121-128.

11. Bustanji Y, Issa A, Mohammad M, Hudaib M, Tawah K, et al. (2010) Inhibition of hormone sensitive lipase and pancreatic lipase by Rosmarinus officinalis extract and selected phenolic constituents. J Med Plants Res 4: 2235-2242.

12. Mohammed A, Gbonjubola VA, Koorbanally NA, Islam MS (2017) Inhibition of key enzymes linked to type 2 diabetes by compounds isolated from Aframomum melegueta fruit. Pharm Biol 55: 1010-1016.

13. Tomlinson TR, Akerele O (1998) Medicinal plants their role in health and biodiversity. Philadelphia, University of Pennsylvania press: 29-40.

14. Oboh G, Akinyemi A, Ademiluyi A (2012) Inhibition of $\alpha$-amylase and $\alpha$ glucosidase activities by ethanolic extract of Telfairia occidentalis (fluted pumpkin) leaf. Asian Pac J Trop Biomed 2: 733-738.

15. Kazeem M, Adamson J, Ogunwande I (2013) Modes of inhibition of aamylase and $\alpha$-glucosidase by aqueous extract of Morinda lucida Benth Leaf. BioMed Res Int 2013: 527570.

16. Gholamhoseinian A, Shahouzehi B, Sharifi-far F (2010) Inhibitory effect of some plant extracts on pancreatic lipase. Int J Pharmacol 6: 18-24.

17. Küpeli E, Aslan M, Gürbüz I, Yesilada E (2004) Evaluation of in vivo biological activity profile of isoorientin. Z Naturforsch 59: 787-790.

18. Alterio AA, Fava DAF, Navarro F (2007) Interaction of the daily ingestion of green tea (Camella sinensis) in the cellular metabolism and the adipose cell promoting emagrecimento. Rev Bras Obes Nut Emag 1: 27-37.

19. Klaus S, Pultz S, Thone-Reineke C, Wolfram S (2005) Epigallocatechin gallate attenuates diet-induced obesity in mice by decreasing energy absorption and increasing fat oxidation. Int J Obes 29: 615-623.

20. Liu X, Kim JK, Li Y, Li J, Liu F, Chen X (2005) Tannic acid stimulates glucose transport and inhibits adipocyte differentiation in 3T3-L1 cells. J Nutr 135:165-171.

21. Mayur B, Sandesh S, Shruti S, Sung-Yum S (2010) Antioxidant and $\alpha$ glucosidase inhibitory properties of Carpesium abrotanoides L. J Medicinal Plant Res 4:1547-1553.

22. Song Y, Manson JE, Buring JE, Howard D, Liu S (2005) Association of dietary flavonoids with risk of type 2 diabetes and markers of insulin resistance and systemic inflammation in women: A prospective study and cross-sectional analysis. J Am Coll Nutr 24: 376-384. 